

\section{Smelly Art and the Hierarchy of Senses}

\section{Borbala Elias}

More and more museums follow the trend of interactive exhibitions. They aim to provide a personal multi-sensory experience, where visitors can touch, move, hear or even smell and actively participate in the exhibition. In spite of their relative popularity, this new style of exhibiting only uses the advantages of technological developments 'to gain ever more "insight" into artefacts' (Howes and Classen 2006, 216), while missing out on other possibilities. This paper seeks to outline why olfactory art pieces tend to be perceived as secondary to visual artefacts in Western cultures, and therefore often excluded from museums (as art pieces) and perceived as of lesser value than their visual counterparts. Moreover, I will briefly elaborate on the question of why certain pieces are valued as art, while others are considered waste. These questions are fairly complex and could be argued from different disciplinary positions; in the following paper, I will present an anthropological interpretation. More precisely, an approach from sensory studies, the still evolving subfield of anthropology, hence the vivid discussion between Howes and Pink (Pink 2010). The essay is divided into two main sections; the first part elaborates on the relationship between senses and value, drawing on Howes' argumentation, the second is a practical example, considering the production of olfactory art and touching on the subject of the difference between artefact and waste, which is based on a discussion with the Viennese artist Bernhard Weber.

Howes highlights that Western cultures almost exclusively value visual artefacts and that the senses that are required to interpret a certain article often determine its value. Howe further argues that the present perception of senses in the Western culture is specific to it, and a result of a historical process (Howes 2003, 3-58; Howes 2006, 199-222). In the $18^{\text {th }}$ and $19^{\text {th }}$ century, scholars from philosophy and anthropology studied the colonies from a highly Eurocentric point of view, contrasting Western and non-Western cultures (Howes 2006, 206). Perceiving their own culture as civilized, and science based while viewing the non-Western cultures as primitive, closer to nature and reliant on their senses. Depicting them as those who 'live a life of the body, rather than a life of the mind' (Howes 2006, 206). Thus, certain characteristics were attributed to them, for instance, heightened hearing, smelling and touch (Howes 2003, 4-5), which were thus classified as the lower senses in contrast to the Western culture valorizing sight above all as well as hearing. As Howes describes: 'Since sight and hearing were traditionally linked with intellectual activity and civilized behavior in European culture, while taste, touch and smell were associated with animality, it was imagined that "primitive" peoples would show a predilection for "lower"or "animal"- in short, "primitive"- senses' (Howes 2003, $4-5)$.

However, this categorization is the result of a Eurocentric interpretation of non-Western cultures. Howes' historical approach emphasizes the cultural specificity of the a) number of senses differentiated b) characteristics contributing to these senses and c) hierarchy between the senses (Howes 2003, 3-58; Howes 2006, 199-222). Arguing that senses should not be regarded as universal categories promoted by Western culture but should be examined in their own merit, in context of a particular culture, Howes suggests using 
language as a source to establish the relationship between a culture and its interpretation of senses (Howes 2003, 9). As for the Western culture, according to Howes, by the $18^{\text {th }}$ $19^{\text {th }}$ century senses were hierarchized, the most prestigious were senses such as vision and hearing, which were associated with the Western culture, followed by the 'lower' senses. By the second half of the $20^{\text {th }}$ century, it was common to believe that 'sight and hearing are the least subjective of the senses and therefore the most suitable for scientific investigation' (Howes 2003, 6). Moreover, technological developments allowed visual and voice recordings to 'reinforce the association of sight and hearing with rationalism by appearing to register cultural expressions in a direct, unmediated, objective fashion' (Howes 2003, 6-7). In other words, recording devices became tools of representing 'culture as purely visual or auditory manifestations' (Howes 2003, 7). This focus on sight and hearing in the Western culture is also present in the museums, up until today. Howes himself) sees museums as sites where a) 'testing and presenting visualizing scientific paradigms' takes place, while the museums themselves are b) 'also sites of surveillance and public order' (Howes 2006, 208. Moreover, he argues that 'the visual emphasis of the museum contributed to the model of colonization in several ways. Artefacts were required to conform to the sensory order of their new homes. This meant being reduced to the visual, or - from a Western perspective - being civilized into the visual. As the artefacts in the museum represented cultures, the peoples providing them also symbolically had their senses and sensory presences disciplined. Through their representative artefacts they were rendered touchless, speechless, smell-less' (Howes 2006, 210-211).

Howes thus defines museums as sites where identity is created, and Western perceptions and values are reinforced, such as in this case the relationship between senses and Western culture. In addition, Howes mentions how cultural items are removed from their cultural context and placed and interpreted in a Western setting. It is also important to note Howes' views on the interactive exhibitions (Howes 2006, 215-216). $\mathrm{He}$ is rather critical, arguing that technology is used to provide visitors with deeper 'insight' and not to present artefacts that require the use of different senses. Based on the, shortly outlined, arguments of Howes, we can conclude that the interpretation of senses is culturally dependent and historically constructed. In the Western culture, senses are strongly hierarchized and linked to certain attributes. While sight and hearing are seen as objective representation of civilized culture, smell, touch and taste are associated with lower senses and therefore often neglected or seen as less valuable. This is furthermore often reinforced by museum exhibitions, which serve as identity and value creator. In particular, sight based focus of exhibitions contributes to reproduction of the association of art and artistic value with visually interpretable artefacts. In case of olfactory art pieces, these are often seen as fun and interesting, but rarely appreciated for their artistic value as for example a painting would be.

Personally, I was very intrigued by the idea of olfactory art, and when Bernhard Weber agreed to meet, I was excited to learn more. The works of this Viennese artist include paintings, scent installations and more recently scented sculptures (website or Facebook). As he told me, the decision to produce olfactory art works was a lucky accident. Out of his personal interest, Weber started to experiment with scent creations and soon after he was exhibiting. Yet, he is very reflective about the relativity of his success with olfactory art. He mentioned that scent installation would not be among the exhibited artefacts in 
a museum such as MUMOK, and that audience enjoys olfactory artwork but tend to perceive it as something rather fun, not appreciating it as they would a visual art piece. Indeed, there has been an increasing debate about the aesthetic properties of 'smelly art' and its future potential to succeed as a serious form of art, even in the so far still visually biased art and museum world (Shiner \& Kriskovets 2007).

But smelly art is not only about smells, but it is also in a sense conceptual art. Behind every scent creation, there is a premeditated concept; Weber recognizes how certain smells create feelings, recall memories or even encourage one to shop particular products. He explains for example that the smell of a new product is used to create the feeling of euphoria, delight and to remind us how good it is to buy something brand new. Thus, we could say that scents might be seen as less valued in the art world, while playing an important role in a consumer society, and for instance sensory branding. Weber sets expectations evoked by scents in contrast to visual experience. Halsall discusses in this respect cross-sensorial art, and elaborates on how artists use artefacts, which require the use of more than one sense, frequently by contrasting sensory expectation (Halsall 2004, 106-108). Weber also employs cross-sensorial art; for instance, he used scent creation to give a luxurious smell to a not so luxurious toilet, while in another instance he recreated a 'new product' smell, which was then used in an empty, not so new room. At some point, Weber was asked to create three smells for a performance: violence, animals, desert. As these scents are rather abstract and associated with fairly negative attributions, another question arises: what makes a good olfactory artifact? Does it necessary have to have a pleasant smell? Weber exhibited an art piece, which concerns this question. He collected scents, which he regarded as waste, which then, from a small container, drop by drop fall into a rather big glass tank. As the different waste scents mix in the tank, a new smell is created. Maybe this is a smell to think with the value of art.

Halsall, Francis. 2004. 'One sense is never enough', Journal of Visual Art Practice 20: 103-122.

Howes, David. 2003. Sensual Relations: Engaging the senses in culture and social theory. Ann Arbor: The University of Michigan Press.

Howes, David, and Classen, Constance. 2006. 'The Museum as Sensescape: Western Sensibilities and Indigenous Artifacts.' In Sensible Objects: Colonialism, Museums and Material Culture, edited by Elizabeth Edwards, Chris Gosden and Ruth Phillips, 199- 222. Oxford: The Wenner-Gren Foundation for Anthropological Research.

Pink, Sarah. 2010. 'The Future of Sensory Anthropology/the Anthropology of the Senses', Social Anthropology 18(3):331-340.

Shiner, Larry and Kriskovets, Yulia. 2007. 'The Aesthetics of Smelly Art', The Fournal of Aesthetics and Art Criticism, 65(3): 273-286. 